\title{
O levantar dos véus da colonialidade em nosso imaginário durante as aulas de Arte
}

João Alberto Rodrigues*

\begin{abstract}
Resumo:
O presente relato origina-se de um recorte de um projeto desenvolvido nas aulas de arte com turmas do segundo ano do Ensino Médio da rede estadual do Rio Grande do Sul em Porto Alegre. Teve por objetivo abordar e propor reflexões sobre o nosso imaginário social colonizado, de viés racista, sexista e elitizado, gerador de silenciamentos e invisibilidades. Ao longo do projeto foram elaborados trabalhos poético-visuais por estudantes abordando África, racismo e outras formas de violência contra a população negra, colonização e representações positivas. Dentre as referências teóricas para o projeto estão Achille Mbembe, para pensar o racismo no imaginário, Lélia Gonzales e Beatriz Nascimento, para articular racismo e sexismo, Alberto Guerreiro Ramos e Frantz Fanon, que ajudam a refletir sobre o complexo de inferioridade em pessoas negras e os trabalhos de Rosana Paulino e Grada Kilomba sobre silenciamentos e mecanismos de opressão. Como resultado, apresento alguns dos trabalhos poéticos desenvolvidos no projeto, os quais não são discutidos em seus aspectos plástico-visuais, mas estabeleço de forma pontual, breves correlações entre algum assunto tratado em aula e algo que apareceu em algum trabalho.
\end{abstract}

\section{Palavras-chave:}

Ensino de Artes Visuais. Imaginário colonizado. Racismo. Silenciamento. Escuta.

\begin{abstract}
:
This report is an excerpt of a project developed in art classes with students of in the second year of a Public High School of the state of Rio Grande do Sul in Porto Alegre. It aimed to approach and propose reflections on our colonized social imaginary of racism, sexism and elitism, which generates silences and invisibilities. Throughout the project, the students elaborated poetic-visual works addressing Africa, racism and other forms of violence against the black population, colonization and positive representations. Among the theoretical references for the project are Achille Mbembe, to think racism in the imaginary, Lélia Gonzales and Beatriz Nascimento, to articulate racism and sexism, Alberto Guerreiro Ramos and Frantz Fanon, who help to reflect on the inferiority complex in black
\end{abstract}

\footnotetext{
* Licenciado e bacharel em Artes Visuais; mestre em Educação; professor de Arte na rede estadual do Rio Grande do Sul no Colégio Estadual Coronel Afonso Emílio Massot. E-mail: ja.rodrigues@hotmail.com.br. ORCID iD: http://orcid.org/0000-0001-7761-923X.
} 
people and the works of Rosana Paulino and Grada Kilomba about silences and mechanisms of oppression. As a result, I present some of the poetic works developed in the project, which are not discussed in their plastic-visual aspects, instead I establish brief punctual correlations between some subject treated in class and something that appeared in some specific work.

\section{Key words:}

Visual Arts teaching. Colonized imaginary. Racism. Silencing. Listening.

\section{(Re)apresentações e (re)aproximações: um exercício para os sentidos}

Como já sublinhado pela psiquiatra baiana Neusa Santos Souza (1983, p. 17), "o óbvio é aquela categoria que só aparece enquanto tal, depois do trabalho de se descortinar muitos véus". Assim, o trabalho de interferir no racismo presente em imaginários sociais colonizados por múltiplos meios, passa por um trabalho constante de apresentar e falar "obviedades" - mas que não o são para a maioria das pessoas. Ainda, pode-se considerar imaginário social, apoiado nas reflexões da historiadora sul-rio-grandense Márcia Janete Espig (2003) sobre este conceito, como uma estrutura que se origina da relação com o real, construindo a realidade e sendo construído por esta, um palco de disputa pelo poder sobre os bens simbólicos e consequentemente sobre as maneiras de se relacionar com estes e de representar as coisas, pessoas e o mundo. Sendo assim uma construção intersubjetiva, sedimentada e movediça, com sucessivas imagens, falas, histórias, medos, desejos e crenças ao longo do tempo e do espaço por uma população.

Aliás, só conhecendo as origens e os mecanismos de opressão e exclusão alimentados por este imaginário social colonizado e abrindo suas feridas pela escuta e pelo diálogo é que criamos a possibilidade de os superarmos um dia. Logo, este projeto se propôs a tratar do baixo número, ainda persistente, de representações positivas negras no cotidiano, na mídia e nas artes; dos conhecidos estereótipos reproduzidos, com seus efeitos essencializantes, reducionistas e naturalizantes, tal como referido pelo teórico jamaicano Stuart Hall (1997) sobre as subjetividades das pessoas; bem como dos entrelaçamentos entre questões étnico-raciais, de gênero e socias na e pela arte e no cotidiano. Trabalhamos, assim, com a Educação das Relações Étnico-Raciais (ERER) e a Lei 11.645/2008. A partir desses diálogos, reflexões e tensões, foram desenvolvidos trabalhos poéticos-visuais em diferentes linguagens das Artes, alguns apresentados ao longo do texto. O projeto aconteceu em 2019, com quatro turmas de $2^{\circ}$ ano do Ensino Médio da rede estadual do Rio Grande do Sul em uma escola de Porto Alegre. O projeto teve duração de cerca de dois meses e meio em aulas de dois períodos semanais de 50 minutos cada.

E, de uma forma geral, as escolas ainda são espaços para presenciarmos esses estereótipos, tanto nas falas como nas escritas de estudantes e docentes; por isso, este é um lugar fundamental de tensionamento constante desse imaginário coletivo. Tal imaginário é resultado das imagens negativas cristalizadas, estereótipos produzidos pelos discursos eurocêntricos no passado e (re)produzidos pela indústria cultural euro-estadunidense posteriormente, permanecendo até a atualidade. Entendendo os estereótipos de acordo com o crítico cultural indiano Homi Bhabha (2013), estes são representações simplificadas e inferiorizantes, caracterizadas pela fixidez, materializando-se em uma negação da alteridade e da mudança, sendo produzidos pelo discurso colonial sobre formas de alteridades raciais, culturais e históricas.

Não é estranho que imagens e discursos atrelados às culturas negro-africanas e indígenas sejam vistas como inferiores, considerando o poder das imagens e do mercado na construção de nossas subjetividades, nossos comportamentos e nossas escalas de valorações numa sociedade de imagens e espetáculo. É comum notarmos, em nossa cultura, a prática de expor as coisas consideradas "boas" e "bonitas" nas diferentes mídias, e nesse sofisticado jogo elaborado entre as mídias dominantes, estas outras culturas pouco aparecem. Isso colabora para um aspecto da lógica de mercado, na qual o que é bom aparece, e o que aparece é bom, como apontou o teórico francês Guy Debord (1997). Assim, se a cultura de matriz negro-africana não 
aparece ou aparece pouco, isso impossibilita a valorização da cultura negra através dos meios dominantes e, consequentemente, faz com que a população negra não seja valorizada.

O filósofo camaronês Achille Mbembe (2018a) nos provoca com a questão de como o nome "África" ao ser invocado, de forma automática, recobre cada corpo e singularidade com um véu opaco, fazendo com que esse nome opere velamentos e apagamentos originários. Estes são efeitos dos discursos totalizantes e inferiorizantes sobre a África, e buscar furar ou levantar esse véu opaco é um exercício constante. Como muito bem assinala Mbembe (2018a, p. 69):

O racismo consiste, pois, em substituir aquilo que é por algo diferente, uma realidade diferente. Além de uma força de deturpação do real e de um fixador de afetos, é também uma forma de distúrbio psíquico, e é por isso que o conteúdo recalcado volta brutalmente à superfície. Para o racista, ver um negro é não ver que ele não está lá; que ele não existe; que ele não é outra coisa senão o ponto de fixação patológica de uma ausência de relação.

Outra ação importante para nos ajudar a pensar sobre as relações entre racismo e arte foi a visita, com as turmas, à exposição Estética da rebeldia (Figura 1) no Museu de Arte do Rio Grande do Sul (MARGS), com xilogravuras e desenhos do artista gaúcho Otacílio Camilo (1959-1989), que era negro, homossexual e oriundo da periferia, e que teve seu trabalho à margem dos espaços oficiais e institucionais da arte da cidade, que eram e são hegemonicamente brancos. Assim, tivemos uma experiência local sobre o debate acerca da representatividade e sobre as dificuldades de encontrar trabalhos de artistas que tiveram sua produção ignorada e marginalizada pelo sistema da arte.

Figura 1 - Exposição Estética da rebeldia

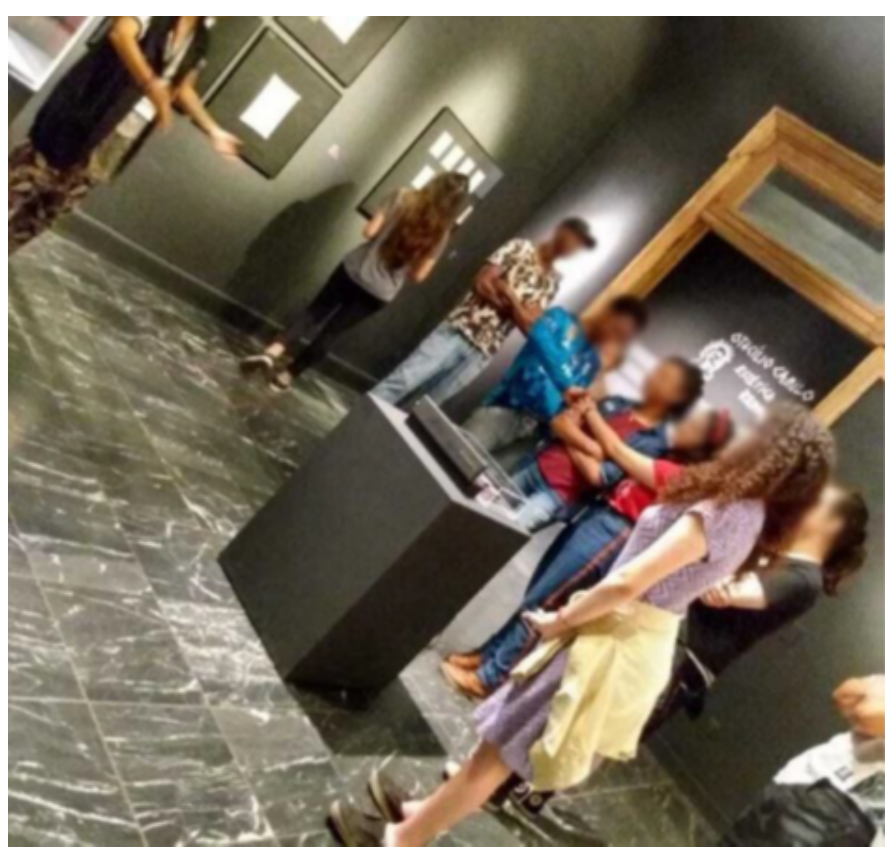

Fonte: Acervo do autor.

\section{O silenciamento e a necessidade da fala e da escuta}

Em conversas introdutórias com as turmas, falei sobre estas relações entre imaginários sociais, racismo e estereótipos. Em uma aula seguinte assistimos ao vídeo da palestra da escritora nigeriana Chimamanda Adichie (2009), O perigo de uma única história, na qual ela conta sobre os diversos absurdos que já ouviu por 
ser escritora e africana e sobre a África. Destaca o quanto é importante ouvir os outros lados das histórias, lembrando sobre o perigo de não se fazer esse exercício crítico, tendo em vista o quanto a colonização sufocou outras histórias. Para pensarmos o quão poderosas são as histórias e as imagens que as acompanham, bem como o quanto se faz necessário disputar e ocupar imaginários, Achille Mbembe (2018a) reflete sobre o quanto o "empreendimento colonial" estabeleceu uma "relação fundamentalmente imaginária", operando por fabulações na tentativa de apresentar como reais aspectos inventados. O efeito do discurso colonial no imaginário, segundo o autor, foi tornar o "signo que chamam de negro e por tabela, o aparente não lugar que chamamos de África, cuja característica é ser não um nome comum e muito menos um nome próprio, mas o indício de uma ausência de obra" (MBEMBE, 2018a, p. 31).

$\mathrm{Na}$ aula seguinte, vimos alguns trabalhos de arte africana contemporânea, pois, ao pensar em África, muitas falas de estudantes apontavam aspectos negativos relativos à África, como a pobreza, as doenças, os conflitos, etc. Assim como, ao falar o que pensavam sobre arte africana, houve comentários que reduziam as produções africanas a máscaras e a corpos pintados. Além destes trabalhos, assistimos a um vídeo sobre a exposição Africa Africans ${ }^{1}$, realizada no Museu Afro-Brasil em 2015, para olharmos um pouco mais da diversidade existente na arte contemporânea africana. Ademais, no que diz respeito à arte negro-africana tradicional, esta foi vista pelo europeu como primitiva e infantil, como afirma o antropólogo congolês Kabengele Munanga (2007). Em um momento seguinte lemos parte do texto "Quando o Ocidente descobre a arte africana", da socióloga brasileira Dilma de Melo Silva (2007) que aborda essas questões apontadas por Munanga. A fala de Chimamanda, bem como o vídeo sobre a exposição Africa Africans e a apresentação de trabalhos de arte contemporânea africana de diferentes linguagens e países, tiveram a função de romper a ideia do continente como algo único e sem diversidade.

Para nos aprofundarmos nestes mecanismos sócio-históricos, lemos parte do texto "Descolonizando

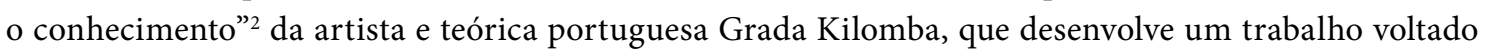
para a violência da colonização, para a memória, seus traumas, para os mecanismos de silenciamento e desumanização e, também, com relação a como era a máscara colocada em pessoas escravizadas, além de abordar o racismo cotidiano. Ao falar sobre a máscara, ela questiona:

Quem pode falar? Quem não pode? E acima de tudo, sobre o que podemos falar? Por que a boca do sujeito Negro tem que ser calada? Por que ela, ele, ou eles/elas têm de ser silenciados/as? O que o sujeito Negro poderia dizer se a sua boca não estivesse tampada? E o que é que o sujeito branco teria que ouvir? (KILOMBA, 2016, p. 1-2).

A boca, segundo a autora, é o orgão de opressão por excelência, por onde ocorrem processos de desumanização (KILOMBA, 2010). Ao final da leitura, assistimos a um trecho de uma de suas performances ${ }^{3}$ com falas racistas ouvidas no dia a dia.

Foi importante ouvirmos Chimamanda para introduzirmos estas questões que foram aprofundadas nessa aula com o texto de Grada Kilomba, que nos lembra das relações de poder que constituem mecanismos racistas e consequentemente sexistas, construídos e perpetuados historicamente sob diferentes formas. Tema sobre o qual a filósofa e ativista estadunidense Angela Davis (2016, p. 181) já havia escrito, ao falar sobre o estupro, colocando que "o racismo sempre encontrou forças em sua habilidade de encorajar a coerção sexual”. Lélia Gonzales (1984), socióloga e ativista mineira, argumentava sobre como mecanismos de opressão, como o racismo, o sexismo e o preconceito de classe se retroalimentam e precisam um do outro. Operando no período colonial como uma maneira de gerar mais pessoas escravizadas, sendo a mulher

\footnotetext{
1. Vídeo sobre a montagem e os bastidores da exposição Africa Africans disponível em: https://youtu.be/dVJv4hUWhmk. Acesso em: 4 ago. 2020.

2. Parte do texto utilizado em aula disponível em: https://drive.google.com/file/d/1W3nnqk9xy_KlxgJdJluo7lkNoCgbZcXb/view?usp= sharing. Acesso em: 4 ago. 2020.

3. Trecho da performance de Plantation Memories, por Grada Kilomba, disponível em: https://youtu.be/ftRjL7E5Y94. Acesso em: 4 ago. 2020 .
} 
escravizada tratada como uma reprodutora de mão de obra, fato também pontuado pela historiadora e ativista sergipana Maria Beatriz Nascimento (2006).

Como desdobramentos destas falas, na aula seguinte, assistimos a um vídeo sobre a artista visual paulista Rosana Paulino (2014), no qual ela fala sobre sua trajetória e trabalho. Sua série Bastidores foi um bom desdobramento para pensar o silenciamento imposto principalmente às mulheres negras e mais pobres, que ainda continua como uma das consequências da violência colonial. De modo análogo, o silenciamento e a violência colonial ficaram evidentes nas discussões ao tratarmos da exposição Assentamento, apresentada no vídeo, cujo trabalho traz as discussões acima comentadas bem como um processo de rehumanização da memória dessas pessoas negras escravizadas.

Concluída essa parte de discussões em aula, demos início ao desenvolvimento dos trabalhos poéticos nas aulas seguintes, processo que durou cerca de um mês. As linguagens ficaram a escolha de cada estudante e grupo. Alguns dos temas abordados foram: máscaras - a tradicional e a imposta pela colonização -, mulheres negras, situações de racismo no cotidiano e a violência na colonização e na atualidade. Apresento agora alguns trabalhos desenvolvidos.

A colagem digital (Figura 2) abordou a violência colonial na África, o processo de desumanização de africanas e africanos e seus efeitos. Em outros trabalhos foi abordado o racismo no cotidiano, como ocorreu em uma série de fotografias (Figura 3). É importante a relação estabelecida no trabalho com camisa (Figura 4) para falar sobre a morte da juventude negra que acontece de forma recorrente por parte do Estado, por meio da ação da polícia, como uma das consequências da violência do racismo que constitui nossa sociedade.

Figura 2 - Colagem digital

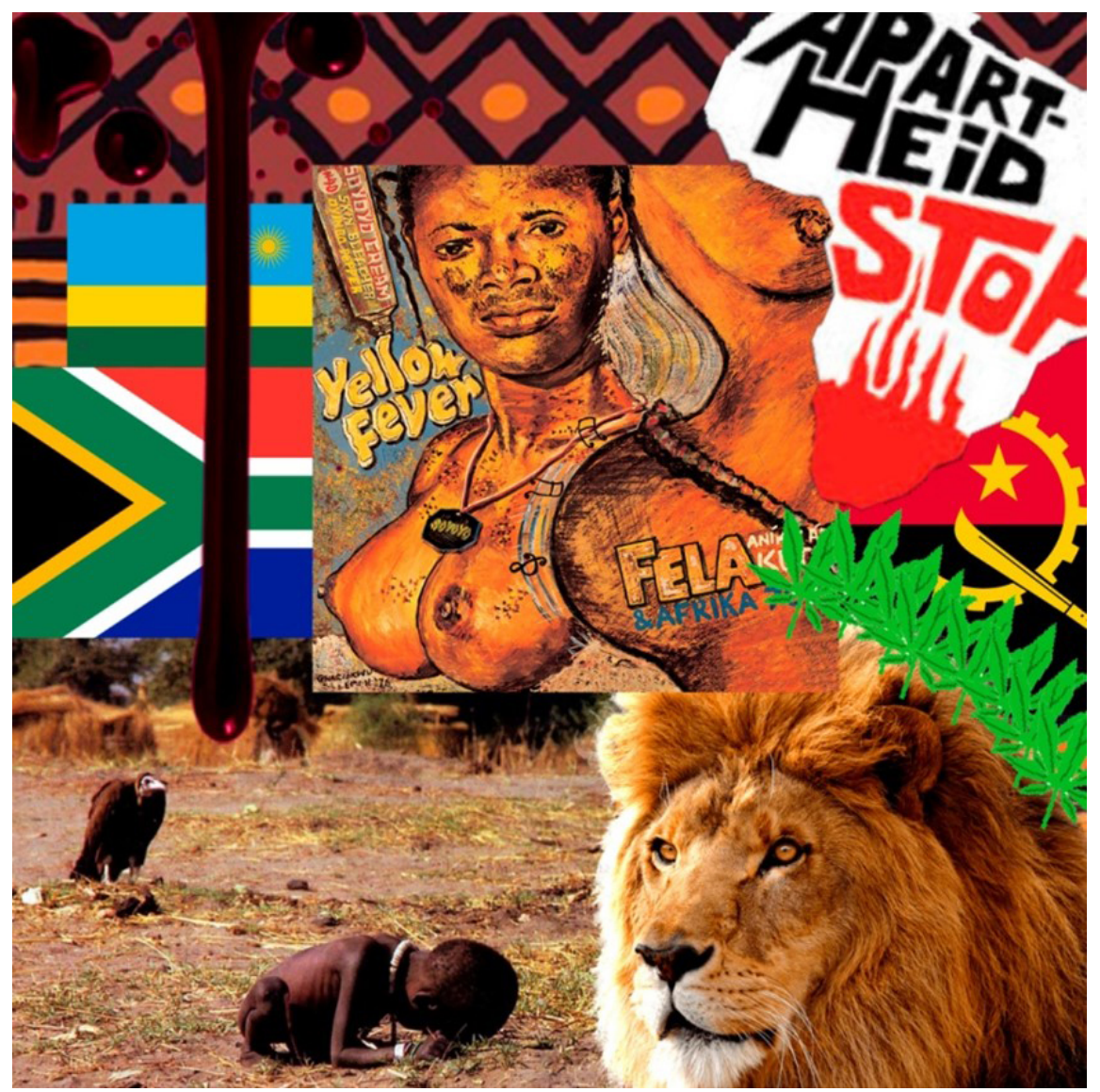

Fonte: Acervo do autor. 
Figura 3 - Fotografias
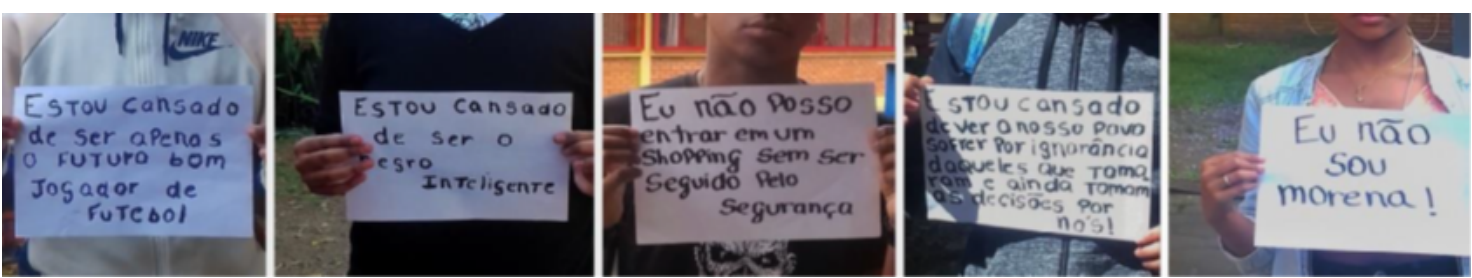

Fonte: Acervo do autor

Figura 4 - Camisa, tinta e cartaz

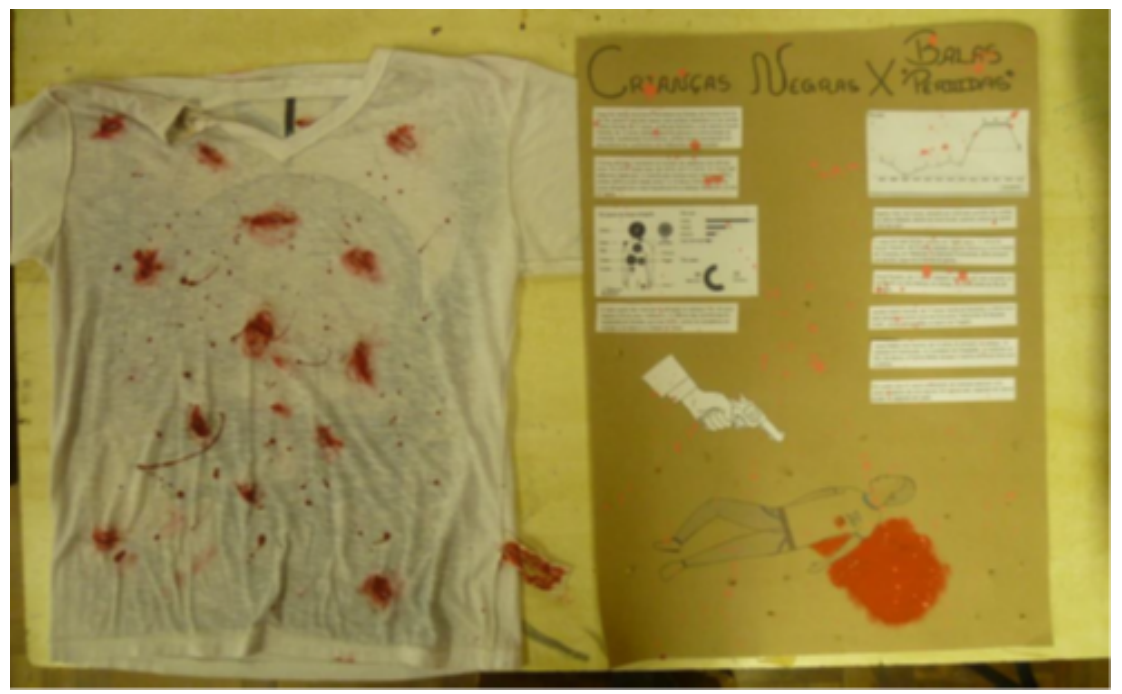

Fonte: Acervo do autor

Aqui estamos diante da violência sobre as pessoas que são percebidas como quase-humanas, os corpos matáveis, tais como eram as pessoas escravizadas, constituindo uma espécie de estado de exceção como norma, como acontece em muitas periferias, se tornando assim uma política de morte, uma necropolítica (MBEMBE, 2018b).

Nesta etapa, algumas estudantes envolveram-se mais nas questões referentes às mulheres negras e ao feminismo negro. A leitura de parte do texto "Feminismo negro", das escritoras e ativistas brasileiras Stephanie Ribeiro e Cidinha da Silva (2018), foi importante para o aprofundamento de suas propostas. Chama a atenção na pintura feita por um menino (Figura 5), que os olhos das mulheres são brancos. Segundo o estudante, era uma referência ao conto “Olhos d'água” (2014), da escritora mineira Conceição Evaristo, no qual uma mulher adulta luta para lembrar a cor dos olhos de sua mãe. 
Figura 5 - Tinta a óleo sobre o papel, $42 \times 30 \mathrm{~cm}$

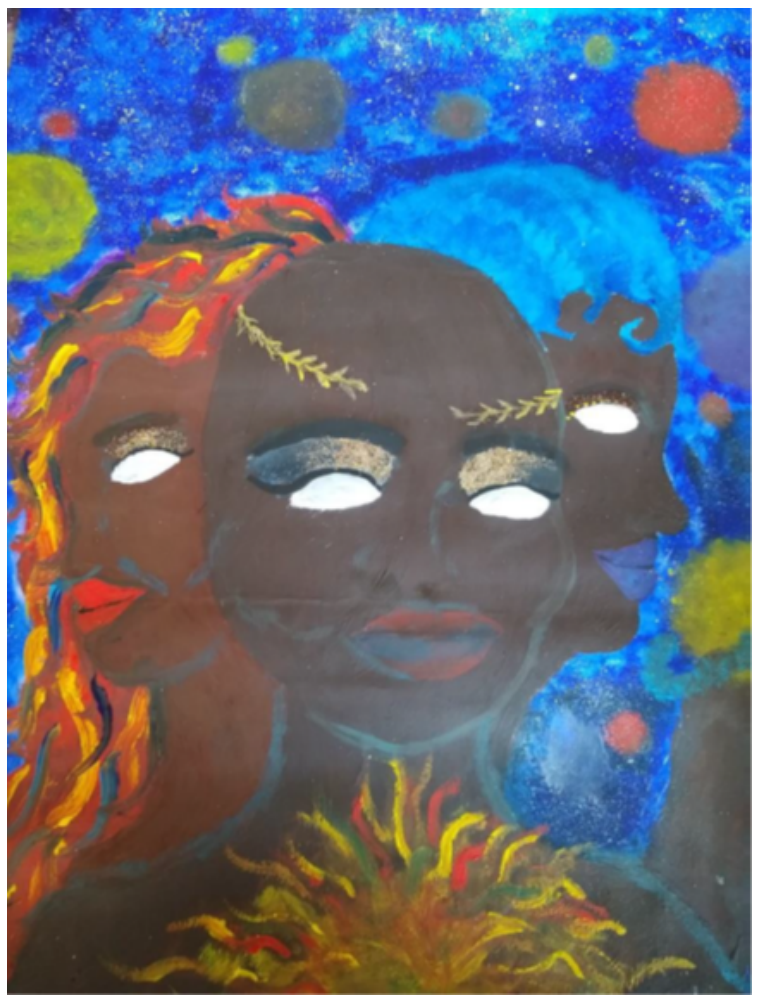

Fonte: Acervo do autor.

E nas assemblagens (Figura 6) temos o cabelo como tema central. Como escreve a pedagoga mineira Nilma Lino Gomes (2008), o cabelo é fundamental para a construção de uma identidade negra fortalecida, uma valorização que vai para além da pessoa, fortalecendo a comunidade negra também.

Figura 6 - Desenho com pirógrafo e assemblagem sobre madeira; linhas, lãs, tecidos e brincos; 40 x $30 \mathrm{~cm}$ cada
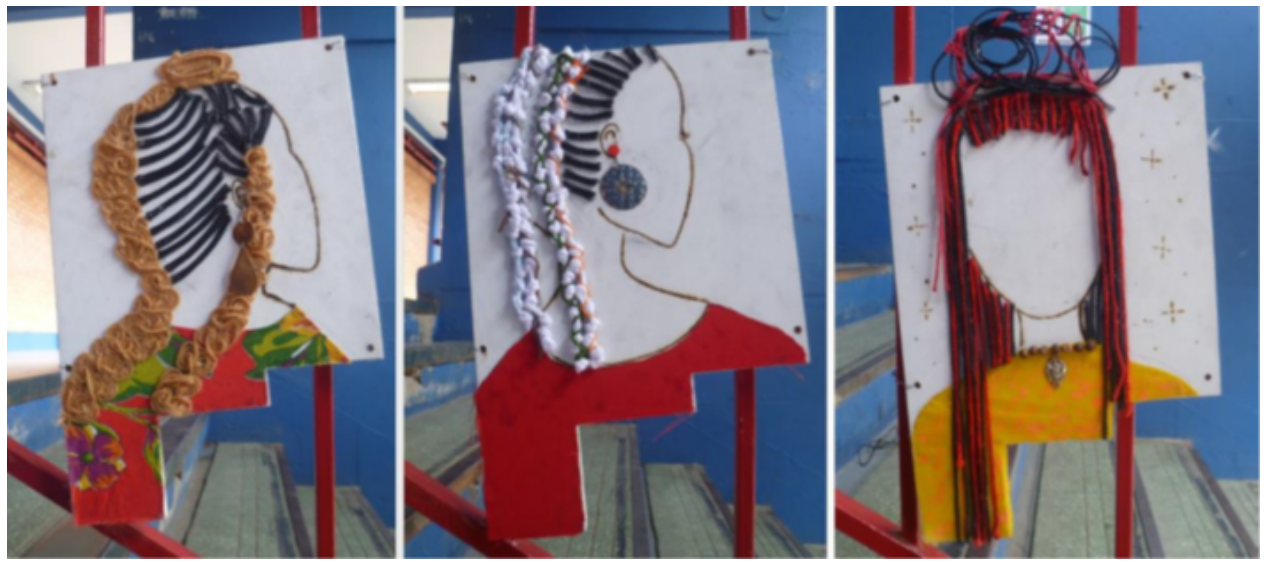

Fonte: Acervo do autor. 
No mural abaixo (Figura 7), temos uma parte do trabalho feito por um grupo de meninas, marcado pelas leituras e interesses sobre as teorias feministas, visando valorizar e fortalecer a união das diferentes mulheres.

\section{Figura 7 - Tinta látex e carvão}

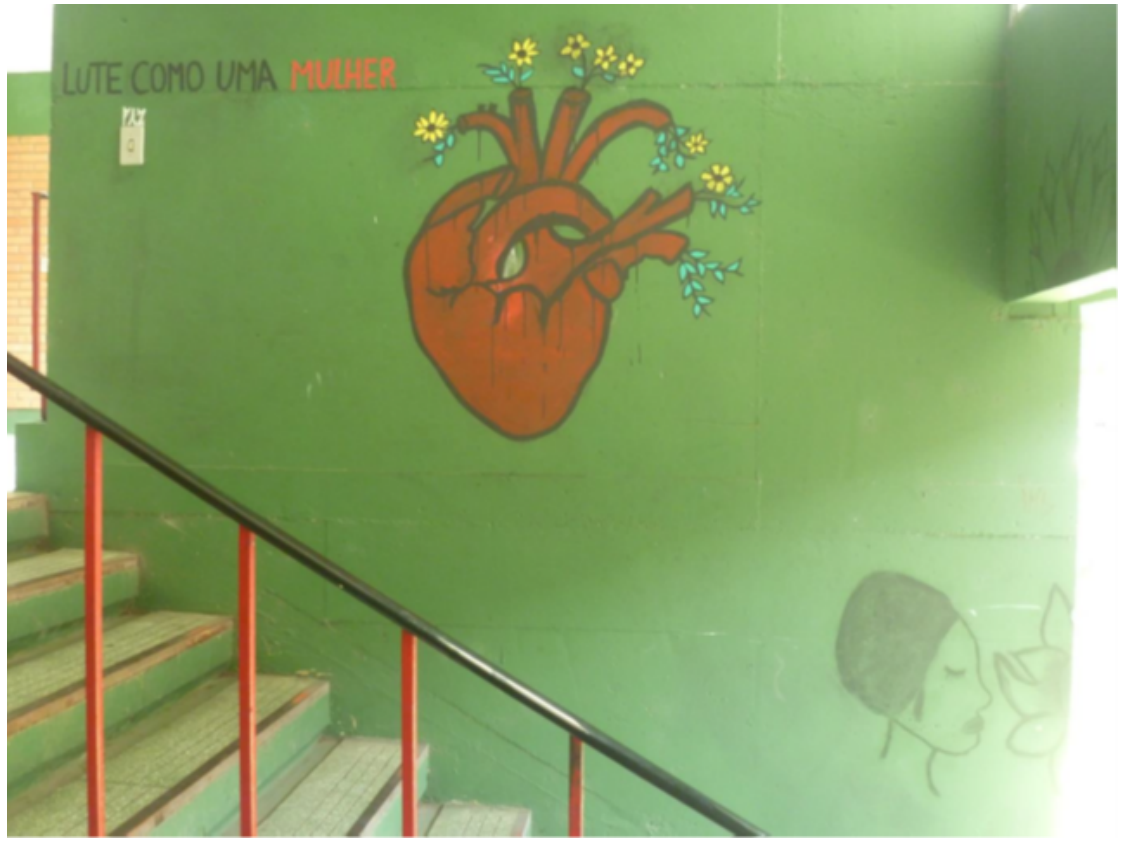

Fonte: Acervo do autor.

\section{Mais algumas palavras e um véu por levantar}

Busquei trabalhar com imagens e discursos que desenquadram, desestabilizando visões sedimentadas ao longo do tempo pelas diferentes mídias, discursos e práticas. Assim, essas micronarrativas poético-visuais criadas por estudantes foram concretizações das intenções que moveram o projeto. Mas fica o registro de que, mesmo exercitando o diálogo sobre as imagens e narrativas contra-hegemônicas nas aulas e durante o desenvolvimento de seus trabalhos, ainda assim houve estudantes que permaneceram nos estereótipos ou tiveram dificuldades de aprofundar outras percepções. Isso nos mostra o quão fortes estes elementos estão estruturados em nós. Isso é um indicativo de que ainda devemos continuar a trabalhar muito nessa direção. Podemos perceber esse aspecto na Figura 8, um mural que tem como tema a máscara e a savana, sendo pintado com quadrados como se fossem pixels, mas, apesar de ficar nestes elementos, podemos tomá-lo como uma ressignificação da máscara tradicional pelo tratamento pop, se olharmos por outro lado. 
Figura 8 - Tinta látex

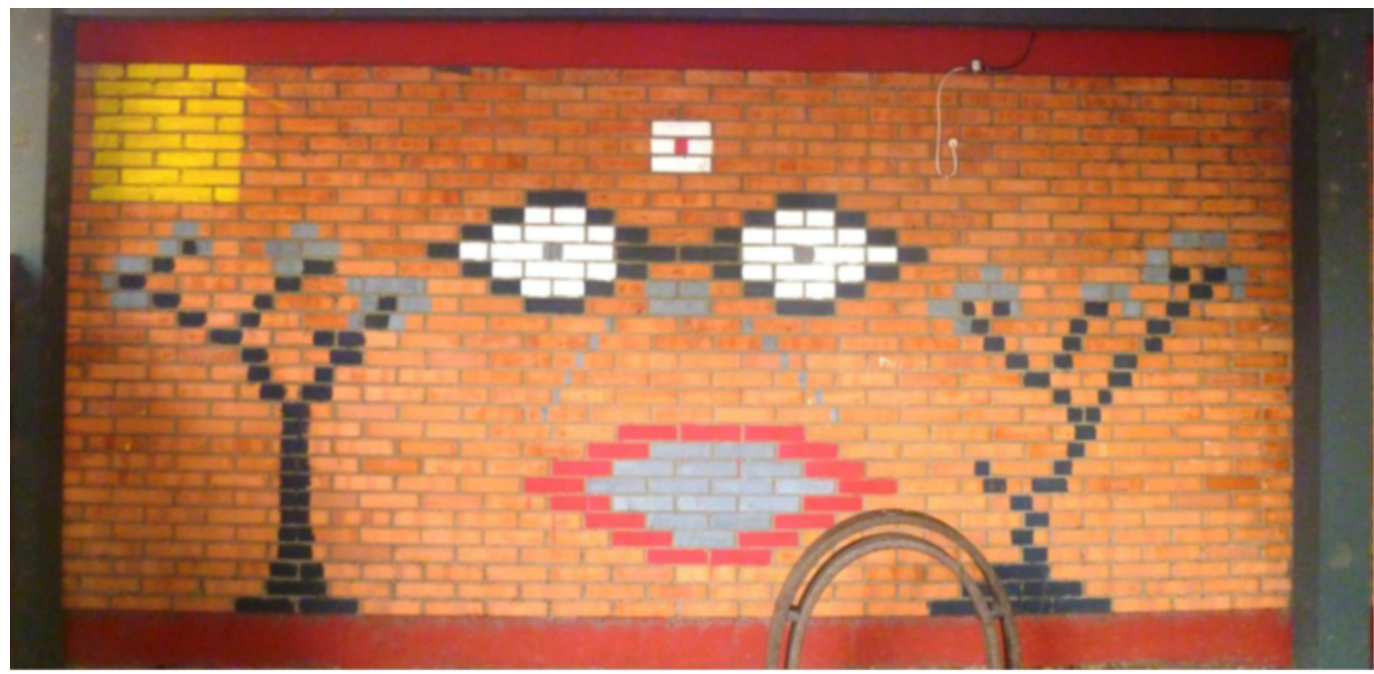

Fonte: Acervo do autor.

Esse projeto foi um exercício de uma prática estético-político-pedagógica voltada para uma educação que se proponha a pensar problemas estruturais, como o racismo e o sexismo, além de explorar a maneira como estas opressões afetam pessoas negras, não brancas e brancas. Faz-se fundamental uma crítica sobre como mecanismos coloniais seguem operando em nosso cotidiano escolar, em falas, silenciamentos, piadas e imagens. Devido a toda espetacularização à qual as pessoas são expostas desde a infância no sentido de valorizar as culturas de matriz europeia e desvalorizar as de matriz africana, tensionar esse imaginário social é um exercício difícil.

Como escreveu Frantz Fanon (2008, p. 34), psiquiatra martinicano:

Todo povo colonizado - isto é, todo povo no seio do qual nasceu um complexo de inferioridade devido ao sepultamento de sua originalidade cultural - toma posição diante da linguagem da nação civilizadora, isto é, da cultura metropolitana. Quanto mais assimilar os valores culturais da metrópole, mais o colonizado escapará da sua selva.

Algo que o sociólogo baiano Alberto Guerreiro Ramos (1981) chamou de uma "patologia cultural”, gerada por esse processo de europeização do mundo, que levou sociedades a guiarem-se por padrões europeus, negando suas características raciais, culturais e históricas, que, por sua vez, leva a um sofrimento psíquico por não alcançar tais padrões. Assim, para vislumbrarmos uma possibilidade de superarmos o racismo, faz-se necessária uma descolonização contínua de nosso imaginário também. Para que, com isso, possamos superar o complexo de inferioridade, de subalternidade, inculcado em nós, que nos leva a rejeitar ou a nos distanciar de aspectos culturais e epistemológicos outros que não os branco-europeus.

Desse modo, ao abrirmos tempos e espaços para a escuta e o diálogo na escola temos a chance de provocar fissuras no sistema de poder gerado em grande parte pelo pacto racial da branquitude, que, como pontua a filósofa paulista Sueli Carneiro (2011), do qual todas as pessoas brancas são beneficiárias, mesmo que nem todas sejam signatárias. O sociólogo e jornalista baiano Muniz Sodré (2015) nos fala sobre a importância do afeto e do sentimento na superação do racismo, que pode nascer de comunidades e parcerias por meio de interações, trabalhos conjuntos e convivências, "em que a alteridade se faça presente de modo prolongado e convivial", não visando uma tolerância fria e distante, mas uma "efetiva partilha dos territórios" (SODRÉ, 2015, p. 299). E quem sabe, assim, consigamos tocar a ideia de "suspender o céu" de que nos fala o ambientalista e liderança indígena Ailton Krenak (2019), ampliando nossos horizontes a um nível existencial, pelo enriquecimento de nossas subjetividades em convivência com as alteridades, algo que nossa época ainda tenta restringir. A escola, por mais que tenha colaborado com a manutenção e a reprodução de mecanismos de opressão, invisibilização e inferiorização desde sua criação, possui o potencial para colaborar na superação destes. 


\section{Referências}

BHABHA, Homi. A outra questão: o estereótipo, a discriminação e o discurso do colonialismo. In: BHABHA, Homi. O local da cultura. 2. ed. Belo Horizonte: Editora UFMG, 2013. p. 117-169.

CARNEIRO, Sueli. Racismo, sexismo e desigualdade no Brasil. São Paulo: Selo Negro, 2011.

DAVIS, Angela Yvonne. Mulheres, raça e classe. São Paulo: Boi Tempo, 2016.

DEBORD, Guy. A sociedade do espetáculo. Rio de Janeiro: Contraponto, 1997.

ESPIG, Márcia Janete. O conceito de imaginário: reflexões acerca de sua utilização pela história. Textura, Canoas, n. 9, p. 49-56, nov. 2003.

FANON, Frantz. Pele negra, máscaras brancas. Salvador: EDUFBA, 2008.

GOMES, Nilma Lino. Sem perder a raiz: corpo e cabelo como símbolos da identidade negra. 2. ed. Belo Horizonte: Autêntica, 2008.

GONZALES, Lélia. Racismo e sexismo na cultura brasileira. Revista Ciências Sociais Hoje, Brasília, DF, n. 2, p. 223-244, 1984.

HALL, Stuart. The spectacle of the "other". In: HALL, Stuart. Representation: cultural representations and signifying practices. London: SAGE, 1997. p. 223-290.

KILOMBA, Grada. “Descolonizando o conhecimento”: uma palestra-performance de Grada Kilomba. Tradução de Jessica Oliveira. João Camillo Penna, Rio de Janeiro, 2016. Disponível em: https://joaocamillopenna.files.wordpress.com/ 2018/05/kilomba-grada-ensinando-a-transgredir.pdf. Acesso em: 4 ago. 2020.

KILOMBA, Grada. The Mask. In: KILOMBA, Grada. Plantation memories: episodes of everyday racism. 2. ed. Münster: Unrast Verlag, 2010.

KRENAK, Ailton. Ideias para adiar o fim do mundo. São Paulo: Companhia das Letras, 2019.

MBEMBE, Achille. Crítica da razão negra. São Paulo: N-1 edições, 2018a.

MBEMBE, Achille. Necropolítica: biopoder, soberania, estado de exceção, política da morte. São Paulo: N-1 edições, $2018 b$.

MUNANGA, Kabengele. A dimensão estética na arte negro-africana tradicional. MAC virtual, São Paulo, 7 jun. 2007. Disponível em: http://www.macvirtual.usp.br/mac/arquivo/noticia/Kabengele/Kabengele.asp. Acesso em: 4 ago. 2020.

NASCIMENTO, Maria Beatriz. A mulher negra no mercado de trabalho. In: RATTS, Alex (org.). Eu sou atlântica: sobre a trajetória de vida de Beatriz Nascimento. São Paulo: Imprensa Oficial, 2006. p. 102-106. Disponível em: https://www.imprensaoficial.com.br/downloads/pdf/projetossociais/eusouatlantica.pdf. Acesso em: 4 ago. 2020.

O PERIGO de uma única história. Intérprete: Chimamanda Ngozi Adichie. Nova Iorque: TEDGlobal, 2009. 1 vídeo (18 min 33 s). Disponível em: https://www.ted.com/talks/chimamanda_ngozi_adichie_the_danger_of_a_single_story/ transcript?language=pt-br. Acesso em: 4 ago. 2020 .

RAMOS, Alberto Guerreiro. O Problema do Negro na Sociologia Brasileira. In: SCHWARTZMAN, Simon (org.). $O$ Pensamento Nacionalista e os "Cadernos de Nosso Tempo". Brasília, DF: Câmara dos Deputados; Biblioteca do Pensamento Brasileiro, 1981. v. 6, p. 39-69.

RIBEIRO, Stephanie; SILVA, Cidinha da. Feminismo negro. In: HOLLANDA, Heloisa Buarque de (org.). Explosão feminista: arte, cultura, política e universidade. São Paulo: Companhia das Letras, 2018. p. 252-300.

ROSANA Paulino. Produção e Direção: Celia Antonacci. Roteiro: Célia Antonacci e Guto Presta. Fotografia: Virgínia Yunes e Célia Antonacci. Edição: Guto Presta. São Paulo:

SILVA, Dilma de Melo. Quando o Ocidente descobre a arte africana. In: BIBLIOTECA entre livros: textos fundamentais para ler e guardar. São Paulo: Duetto, ed. esp. n. 6, 2007. p. 20-23.

SODRÉ, Muniz. Claros e escuros: identidade, povo, mídia e cotas no Brasil. 3. ed. Petrópolis, Rio de Janeiro: Vozes, 2015.

SOUZA, Neusa Santos. Tornar-se negro: as vicissitudes da identidade do negro brasileiro em ascensão social. Rio de Janeiro: Edições Graal, 1983.

Data de submissão: 11/08/2020

Data de aceite: 04/10/2020 